Article

\title{
Studies on Chemical IR Images of Poly(hydroxybutyrate-co-hydroxyhexanoate)/ Poly(ethylene glycol) Blends and Two-Dimensional Correlation Spectroscopy
}

\author{
Yeonju Park ${ }^{1}$, Sila Jin ${ }^{1}$, Yujeong Park ${ }^{1}$, Soo Min Kim ${ }^{1}$, Isao Noda ${ }^{2,3, * \mathbb{D}}$, Boknam Chae ${ }^{4}$ \\ and Young Mee Jung ${ }^{1, *(\mathbb{D})}$ \\ 1 Department of Chemistry, Institute for Molecular Science and Fusion Technology, \\ Kangwon National University, Chuncheon 24341, Korea; yeonju4453@kangwon.ac.kr (Y.P.); \\ jsira@kangwon.ac.kr (S.J.); po01266@naver.com (Y.P.); italy3255@naver.com (S.M.K.) \\ 2 Department of Materials Science and Engineering, University of Delaware, Newark, DE 19716, USA \\ 3 Danimer Scientific, 140 Industrial Blvd., Bainbridge, GA 39817, USA \\ 4 Pohang Accelerator Laboratory, POSTECH, Pohang 37673, Korea; cbn@postech.ac.kr \\ * $\quad$ Correspondence: noda@udel.edu (I.N.); ymjung@kangwon.ac.kr (Y.M.J.); Tel.: +82-33-250-8495 (Y.M.J.)
}

Received: 7 February 2019; Accepted: 13 March 2019; Published: 17 March 2019

\begin{abstract}
Biodegradable poly-[(R)-3-hydroxybutyrate-co-(R)-3-hydroxyhexanoates] (PHBHx) have been widely studied for their applications in potentially replacing petroleum-based thermoplastics. In this study, the effect of the high molecular weight $(M n=3400)$ poly(ethylene glycol) (PEG) blended in the films of PHBHx with different ratios of PEG was investigated using chemical FTIR imaging. Chemical IR images and FTIR spectra measured with increasing temperature revealed that PEG plays an important role in changing the kinetics of PHBHx crystallization. In addition, two-dimensional correlation spectra clearly showed that thermal properties of PHBHx/PEG blend film changed when the blending ratio of $\mathrm{PHBHx} / \mathrm{PEG}$ were 60/40 and 50/50. Consequently, PEG leads to changes in the thermal behavior of PHBHx copolymers.
\end{abstract}

Keywords: biodegradable polymer; IR imaging; 2D-COS; blend

\section{Introduction}

Environmental pollution has been a serious issue over the last few decades. Plastic pollution especially is a huge problem. Because the degradation rate of plastic is much slower than that of production, and its durability rate and recycled portion is as low as $9 \%[1,2]$, it is constantly accumulating on the earth. There have been many efforts to reduce plastic consumption or promote plastic recycling, yet only some have had limited success so far. Therefore, the development of easily degradable polymers has received significant interest $[3,4]$ as an alternative approach.

Poly(hydroxyalkanoates) (PHAs) produced by a variety of bacteria are well-known biodegradable polymers [5-7]. Among them, poly-[(R)-3-hydroxybutyrate) (PHB) is one of the well-studied biodegradable polymers due to its potential to replace petroleum-based thermoplastics [5]. However, thermal, mechanical and chemical properties of PHB homopolymer by itself are somewhat limited for wider applications. To improve the properties of PHB, many attempts have been studied by copolymerization [2,8-12] and blending [13-15] with the other polymers. The PHB-based copolymers have been extensively studied using infrared (IR) [16-19] and Raman [8,10,20] spectroscopies, wide-angle X-ray scattering (WAXS) [11,20,21], X-ray diffraction (XRD) [22,23], differential scanning calorimetry (DSC) [24,25], and so on. 
As polymer systems are very complicated to investigate using only conventional spectroscopic analysis, many kinds of advanced analytical methods, such as the secondary derivative, chemometrics, and two-dimensional correlation spectroscopy (2D-COS) analysis have been used. Among them, 2D-COS is a very powerful and reliable analytical method for polymer study [26-34]. 2D-COS can sort out very important and interesting information in the system, which is sometimes scarcely detected in conventional 1D spectral analysis. It has many powerful advantages to greatly enhance spectral resolution, to explore inter- or intra-molecular interactions in the system, and to decide the sequential order of the events in the system [35-38].

In our previous study [30], we reported the influence of poly(ethylene glycol) (PEG) molecular weight $(\mathrm{Mn}=400,1500$, and 3400) on the thermal properties of poly-[(R)-3-hydroxybutyrate-co(R)-3-hydroxyhexanoate) (PHBHx, HHx $=6.9 \mathrm{~mol} \%$ )/PEG blends thin film. We found that PEG with a lower molecular weight $(M n=400)$ was completely miscible with PHBHx while PEG 1500 and 3400 were only partially miscible. We also discovered that a new amorphous band at $1744 \mathrm{~cm}^{-1}$, which corresponds to the amorphous mixture of PHBHx and PEG 400, was exhibited only in the 70/30 PHBHx/PEG 400 blend thin film. The possible mixing behavior of a higher molecular weight PEG blended with PHBHx is now explored. In this study, IR mapping was performed to examine the existence of domains in films of PHBHx/PEG $(M n=3400)$ blends. Hyperspectral imaging study provides the localized spatial distributions of multicomponent and multiphase samples [39,40]. Each chemical IR images of PHBHx/PEG with different blending ratios were obtained with different temperatures. The effect of PEG incorporation on PHBHx copolymers was also investigated using temperature-dependent FTIR spectra and 2D-COS.

\section{Materials and Methods}

Biodegradable PHBHx (HHx $=6.9 \mathrm{~mol} \%)$ copolymer was supplied by the Procter \& Gamble Company (Cincinnati, OH, USA) and was purified using process reported previously [30]. PEG $(M n=3400)$ purchased from Sigma-Aldrich Co., Ltd. (St. Louis, MO, USA) was used without further purification.

Blend samples of PHBHx ( $\mathrm{HHx}=6.9 \mathrm{~mol} \%)$ with different blending ratios of PEG $(\mathrm{Mn}=3400)$ were prepared by dissolving them together in chloroform. The blending ratios of PHBHx/PEG blends were 70/30, 60/40 and 50/50. Then PHBHx/PEG blend solution was spun onto a Pt-coated silicon wafer at $1500 \mathrm{rpm}$ for $30 \mathrm{~s}$ and subsequently placed under vacuum at $60^{\circ} \mathrm{C}$ for $4 \mathrm{~h}$ to completely evaporate the residual solvent. The thickness of spin-coated film of PHBHx/PEG blends (70/30, 60/40 and 50/50) was near $5 \mu \mathrm{m}$ (see the SEM image of cross section of spin-coated film of PHBHx/PEG blend shown in Figure S1).

FTIR spectra and chemical images of PHBHx/PEG blends with increasing temperature (from 30 to $160^{\circ} \mathrm{C}$, interval $10 \mathrm{~min}$ ) were measured by using a Bruker Vertex 80/v FTIR spectrometer equipped with a Hyperion 3000 at the 12D IRS beamline of the Pohang Accelerator Laboratory (PAL). They were conducted with $4 \mathrm{~cm}^{-1}$ resolution using a $64 \times 64 \mathrm{MCT}$ focal plane array (FPA) detector in ATR mode with a $15 \times$ objective. Data were analyzed using Bruker OPUS 7.0 imaging software. FTIR images displayed using chemical images of $\mathrm{C}=\mathrm{O}$ stretching region at each temperature.

Before 2D-COS analysis for each set of temperature-dependent FTIR spectra of PHBHx/PEG blend films, which were extracted from each chemical image of PHBHx/PEG blends, we performed the baseline correction with PLS_Toolbox 8.7 software (Eigenvector Research, Inc., Wenatchee, WA, USA) for MATLAB R2018b (The Mathworks Inc., Natick, MA, USA). Synchronous and asynchronous 2D correlation FTIR spectra were obtained using MATLAB software. The red and blue lines in 2D correlation spectra displayed positive and negative cross peaks, respectively.

\section{Results and Discussion}

In this study, we focused on the $\mathrm{C}=\mathrm{O}$ stretching region $\left(1850-1650 \mathrm{~cm}^{-1}\right)$ due to the absence of the absorption by PEG to investigate the influence of PEG on PHBHx. Figures 1-3 display chemical 
images of $\mathrm{C}=\mathrm{O}$ stretching region at each temperature of $\mathrm{PHBHx} / \mathrm{PEG}=70 / 30,60 / 40$ and 50/50 blend films, respectively. As shown in Figures 1-3, chemical images of PHBHx/PEG = 70/30, 60/40 and $50 / 50$ blends dramatically changed around $60-80{ }^{\circ} \mathrm{C}$ and $130-140{ }^{\circ} \mathrm{C}$. It is in good agreement with the DSC results from our previous study [30]. The change at $60-80{ }^{\circ} \mathrm{C}$ is related to the $T_{\mathrm{m}}$ of PEG while the change at $130-140^{\circ} \mathrm{C}$ is related to the $T_{\mathrm{m}}$ of $\mathrm{PHBHx}$. With the increasing PEG content, chemical images changed near the $T_{\mathrm{m}}$ of PEG at $50{ }^{\circ} \mathrm{C}$. This observation means that the PHBHx and PEG in these samples have different thermal properties. In other words, they are not fully mixed, in contrast to our previously study [30].
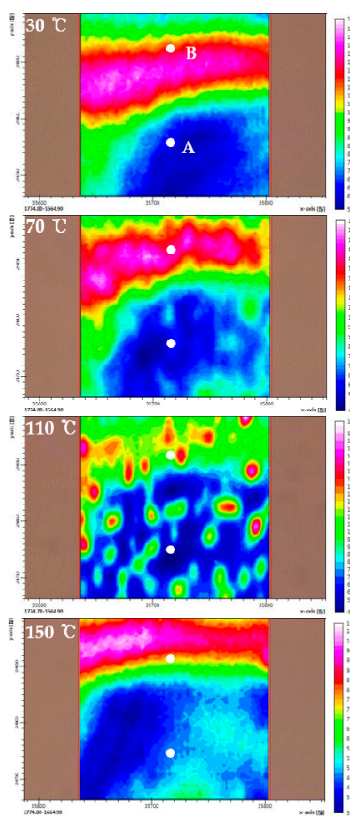
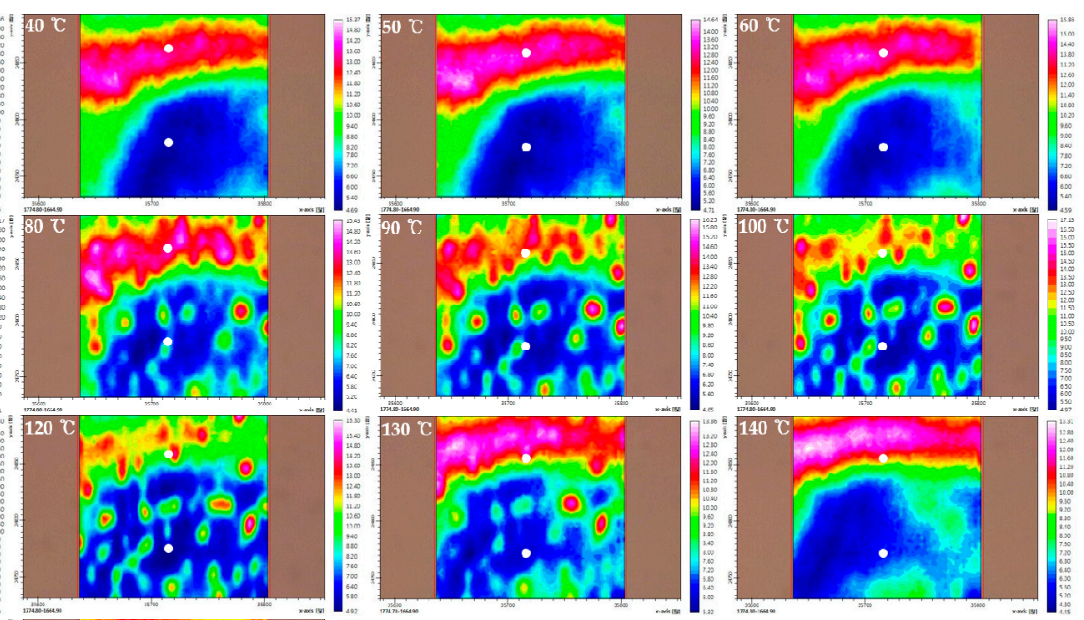

Figure 1. Chemical images of $\mathrm{C}=\mathrm{O}$ stretching region at each temperature of poly-[(R)-3-hydroxybutyrateco-(R)-3-hydroxyhexanoates] (PHBHx)/poly(ethylene glycol) (PEG) = 70/30 blend film.
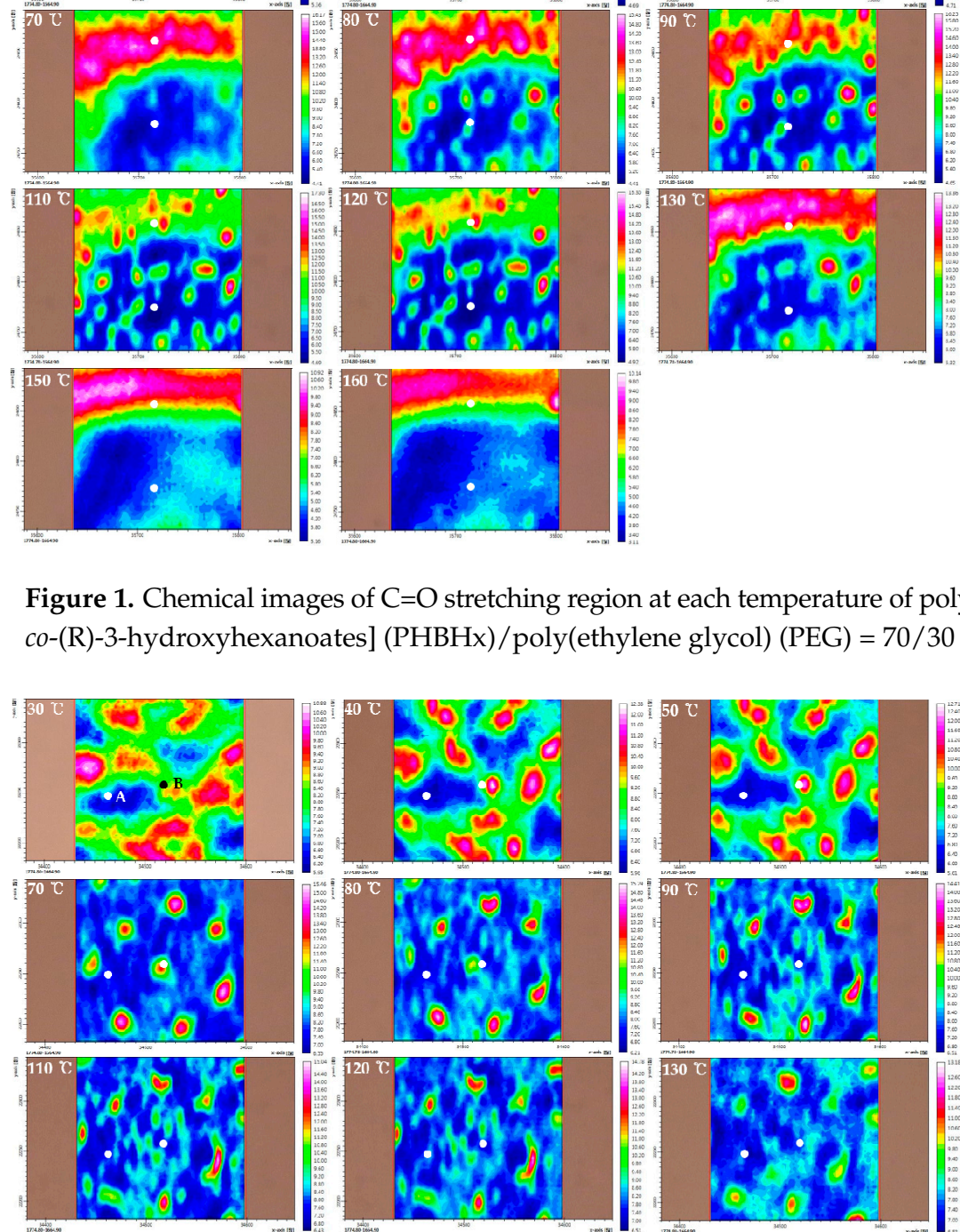

at each temperature of poly-[(R)-3-hyd
ne glycol) $(\mathrm{PEG})=70 / 30$ blend film.
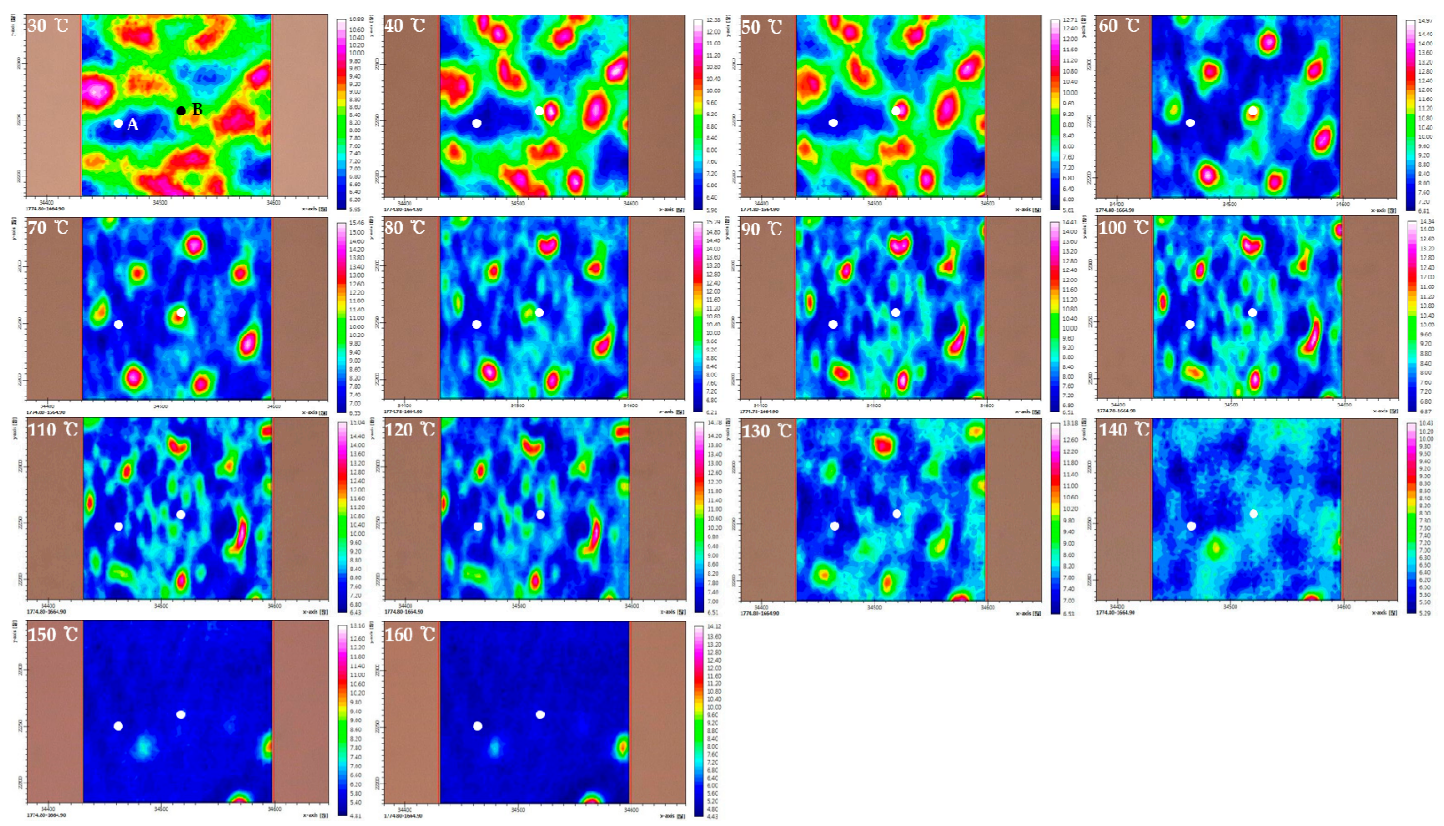

Figure 2. Chemical images of $\mathrm{C}=\mathrm{O}$ stretching region at each temperature of $\mathrm{PHBHx} / \mathrm{PEG}=60 / 40$ blend film. 


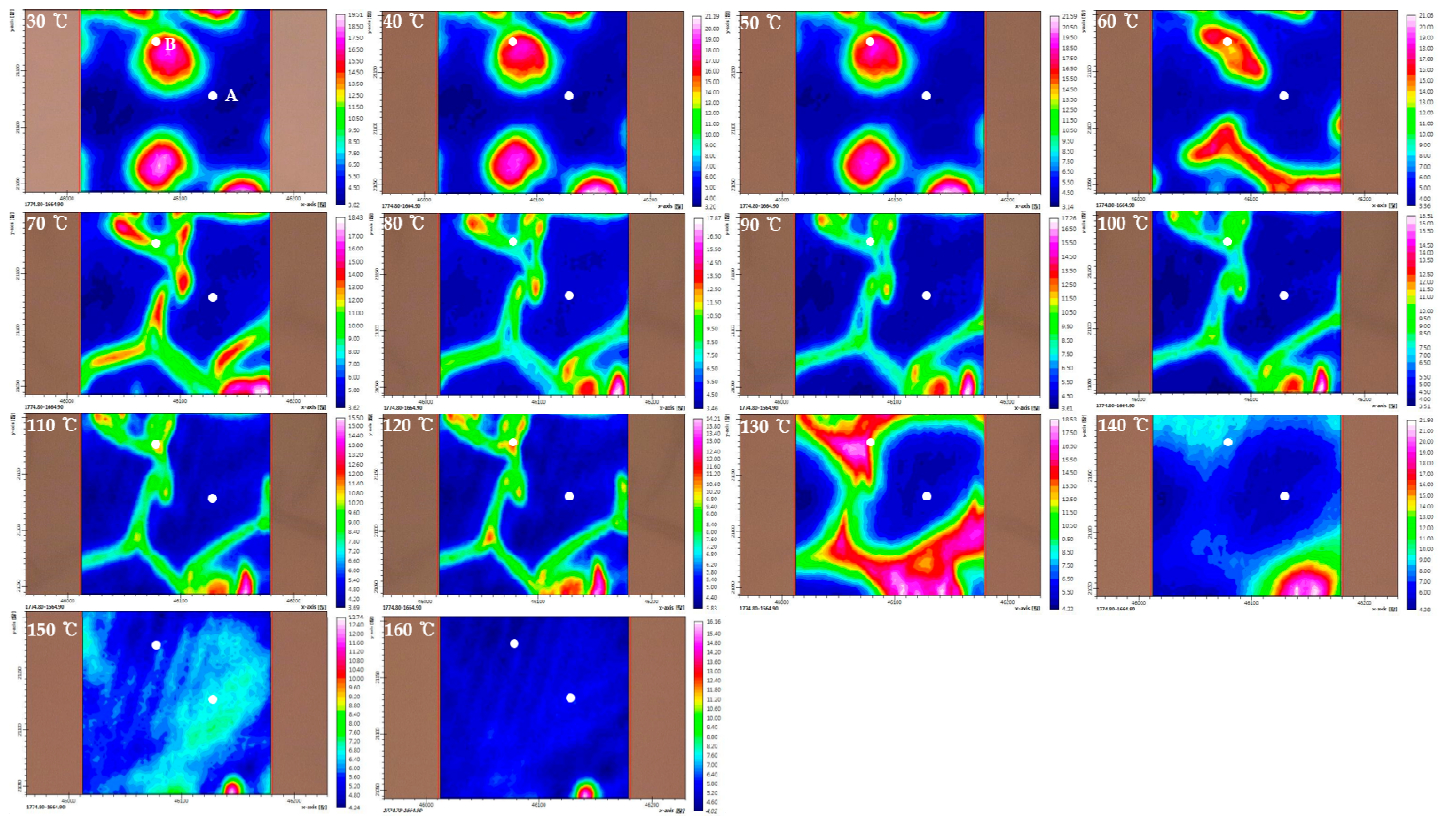

Figure 3. Chemical images of $\mathrm{C}=\mathrm{O}$ stretching region at each temperature of $\mathrm{PHBHx} / \mathrm{PEG}=50 / 50$ blend film.

To better understand the thermal behavior of each domain, we analyzed FTIR spectra extracted at different positions in the chemical images. Position A (lowest part) and B (highest part) on the chemical image have been marked as filled circles. Figure 4 displays the temperature-dependent FTIR spectra extracted at parts A and B in Figures 1-3. The crystalline C=O stretching band at 1722 (or 1725) $\mathrm{cm}^{-1}$ decreases with increasing temperature, while the amorphous $\mathrm{C}=\mathrm{O}$ stretching band at $1735 \mathrm{~cm}^{-1}$ increases with temperature. The shift of carbonyl stretching vibration from $1722 \mathrm{~cm}^{-1}$ to a higher wavenumber around $1735 \mathrm{~cm}^{-1}$ for the amorphous component is a reflection of the reduced hydrogen bond interactions compared to the crystalline phase [41,42]. In the temperature-dependent FTIR spectra of parts A and B in PHBHx/PEG = 70/30 blend films (as shown in Figure 4A,B), the tendency of intensity changes of two bands at 1722 and $1735 \mathrm{~cm}^{-1}$ were similar, even though they had different absorbance values. This result probably means that differences in the chemical image shown in Figure 1 were resulting primarily from thickness variations. In the Figure 4C-F, the intensity changes of two bands at 1722 (or 1725) and $1735 \mathrm{~cm}^{-1}$ as a function of temperature are clearly different in parts A and B. Particularly, in the temperature-dependent FTIR spectra of part B in PHBHx/PEG $=50 / 50$ blend film, a band at $1725 \mathrm{~cm}^{-1}$ was shifted to lower wavenumber (around $1722 \mathrm{~cm}^{-1}$ ) with increasing temperature. This observation indicates that PEG plays an important role in changing the kinetics and degrees of PHBHx crystallization. In other words, PEG $(M n=3400)$ might have influenced the PHBHx crystallization behavior, because PEG and PHBHx were not fully mixed. Zhao et al., reported that the DSC results of the PHB/PEG blend showed that the degree of crystallinity of PHB changed with different PEG contents [43]. This is in good agreement with our results. As shown in Figure 4E, however, intensity changes of crystalline $\mathrm{C}=\mathrm{O}$ stretching band at part $\mathrm{A}$ in $\mathrm{PHBHx} / \mathrm{PEG}=50 / 50$ blends are not greater than the corresponding amorphous $\mathrm{C}=\mathrm{O}$ stretching band. This result indicates that PEG may have more influence on the amorphous $\mathrm{C}=\mathrm{O}$ stretching mode than the crystalline $\mathrm{C}=\mathrm{O}$ stretching mode.

To furthermore understand PEG's effect on PHBHx crystallization in depth, 2D-COS was applied to the temperature-dependent FTIR spectra of PHBHx $/ \mathrm{PEG}=70 / 30,60 / 40$ and 50/50 blend films. Figures 5-7 are the 2D correlation spectra obtained from Figure 4.

The synchronous 2D correlation spectra at parts A and B of PHBHx $/ \mathrm{PEG}=70 / 30$ are quite similar as shown in Figure 5A,C. Two cross peaks at $(1723,1738)$ and $(1712,1723) \mathrm{cm}^{-1}$ were observed in their corresponding asynchronous 2D correlation spectra as shown in Figure 5B,D. Three bands at 1738, 
1723 and $1712 \mathrm{~cm}^{-1}$ correspond to amorphous, less-ordered crystalline and well-ordered crystalline $\mathrm{C}=\mathrm{O}$ stretching modes. This result indicates that differences in chemical images (shown in Figure 1) reflect thickness variation, which is in good agreement with the results in Figure 4A,B.

However, the asynchronous 2D correlation spectra of PHBHx/PEG $=60 / 40$ shown in Figure 6B,D are very different. There is one cross peak at $(1723,1738) \mathrm{cm}^{-1}$ in Figure $6 \mathrm{~B}$ and at $(1715,1723) \mathrm{cm}^{-1}$ in Figure 6D. The variations of two bands corresponding to the less-ordered crystalline and amorphous $\mathrm{C}=\mathrm{O}$ stretching modes appeared at part $\mathrm{A}$, while those for two crystalline (well-ordered and less-ordered crystalline) bands appeared at part B in the PHBHx $/$ PEG $=60 / 40$ blend.
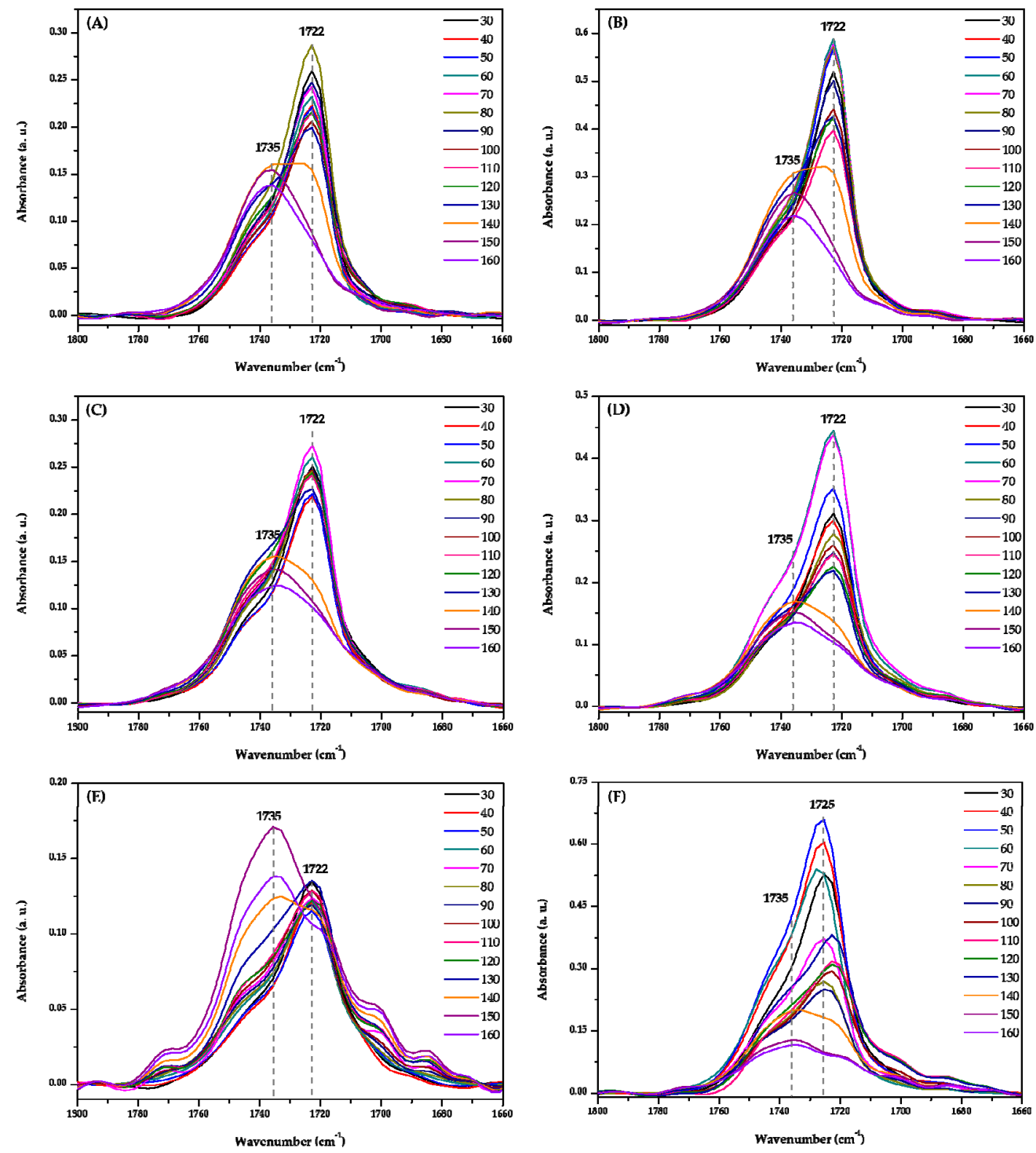

Figure 4. Temperature-dependent FTIR spectra extracted at parts $(\mathbf{A}, \mathbf{C}, \mathbf{E}) \mathrm{A}$ and $(\mathbf{B}, \mathbf{D}, \mathbf{F}) \mathrm{B}$ in Figures 1-3, respectively.

In the Figure $7 \mathrm{~B}, \mathrm{D}$, two cross peaks at $(1738,1748)$ and $(1720,1738) \mathrm{cm}^{-1}$ and one cross peak at $(1720,1736) \mathrm{cm}^{-1}$ appeared, respectively. A new amorphous band at $1748 \mathrm{~cm}^{-1}$ was observed at part A in the PHBHx/PEG = 50/50 blend, which is assigned to the amorphous mixture of PHBHx and PEG [30]. It confirms that with increasing PEG content, partially miscible structures may appear in the PHBHx $/$ PEG $=50 / 50$ blend. 
While PEG and PHBHx are only partially miscible, the presence of PEG significantly affects the crystallization behavior of PHBHx, especially the amorphous part in PHBHx. As the mixing of PEG, which acts as a plasticizer, will substantially decrease the $T_{\mathrm{g}}$ and increase the molecular mobility of PHBHx, we expect the crystallization kinetics will be affected. This effect leads to different thermal behavior of PHBHx copolymers.
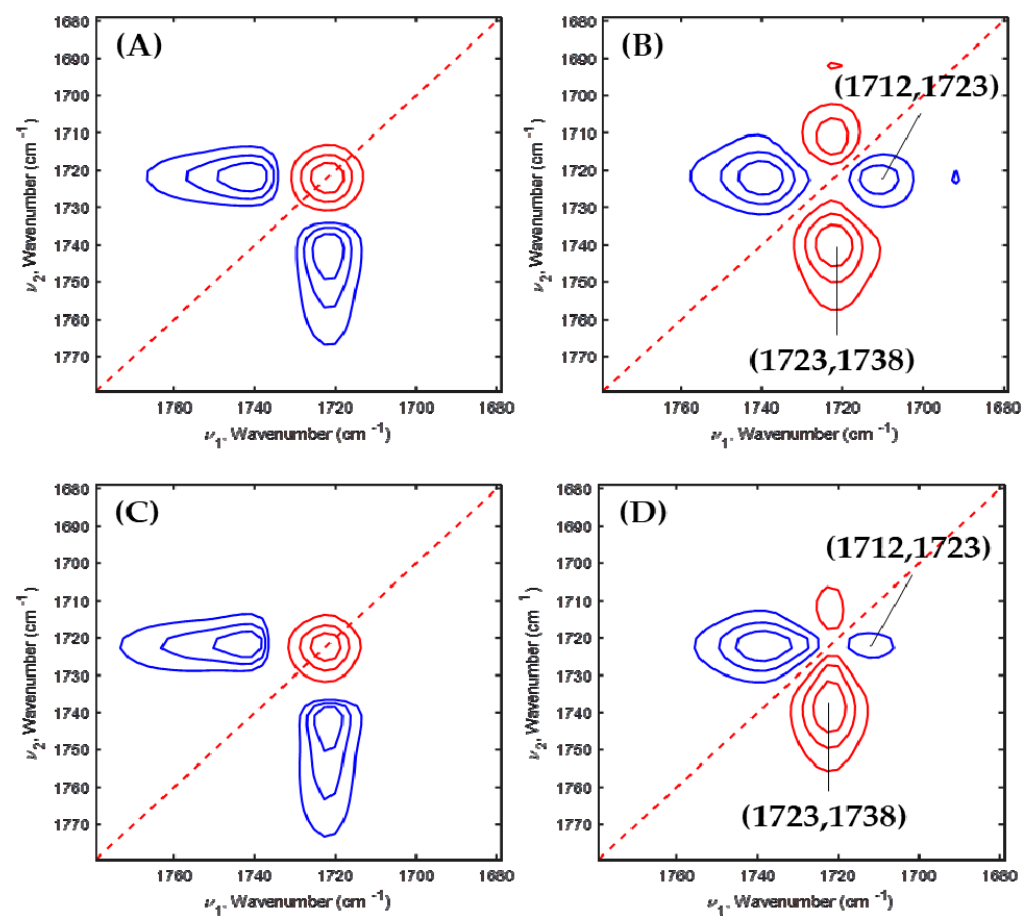

Figure 5. Synchronous (A,C) and asynchronous (B,D) 2D correlation spectra obtained from Figure 4A,B.
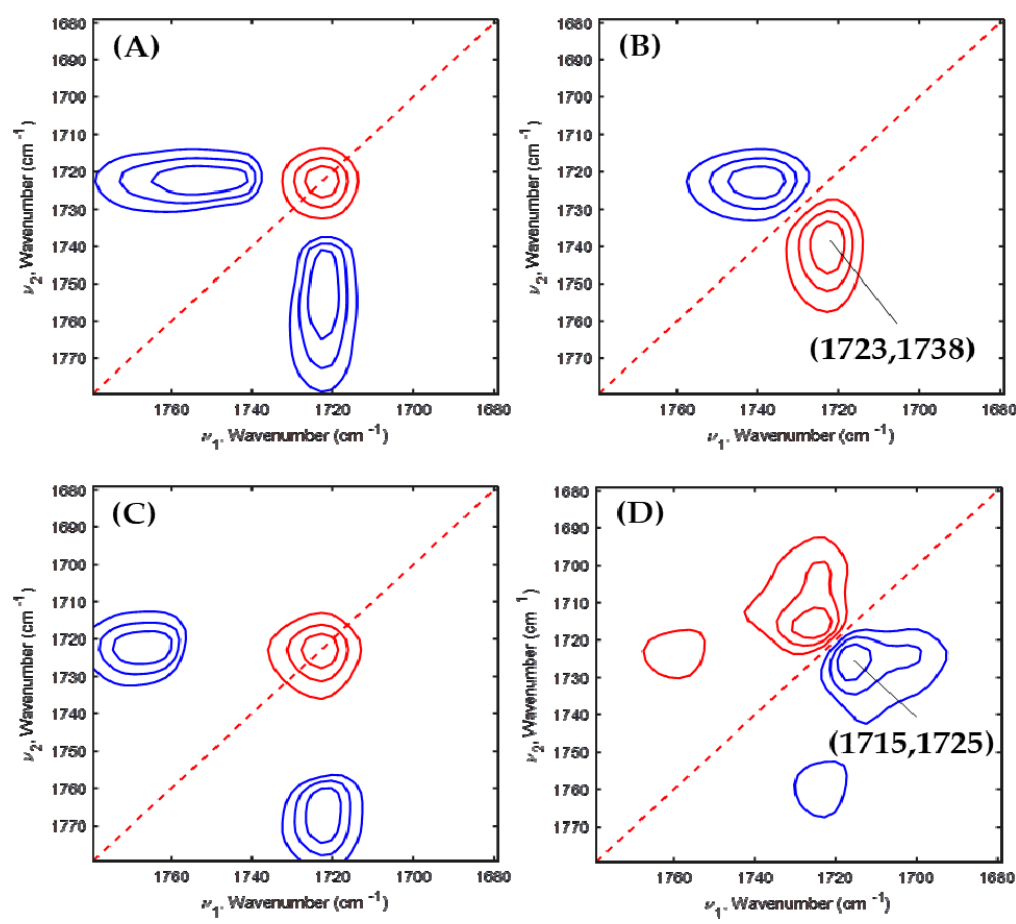

Figure 6. Synchronous $(A, C)$ and asynchronous (B,D) 2D correlation spectra obtained from Figure 4C,D. 

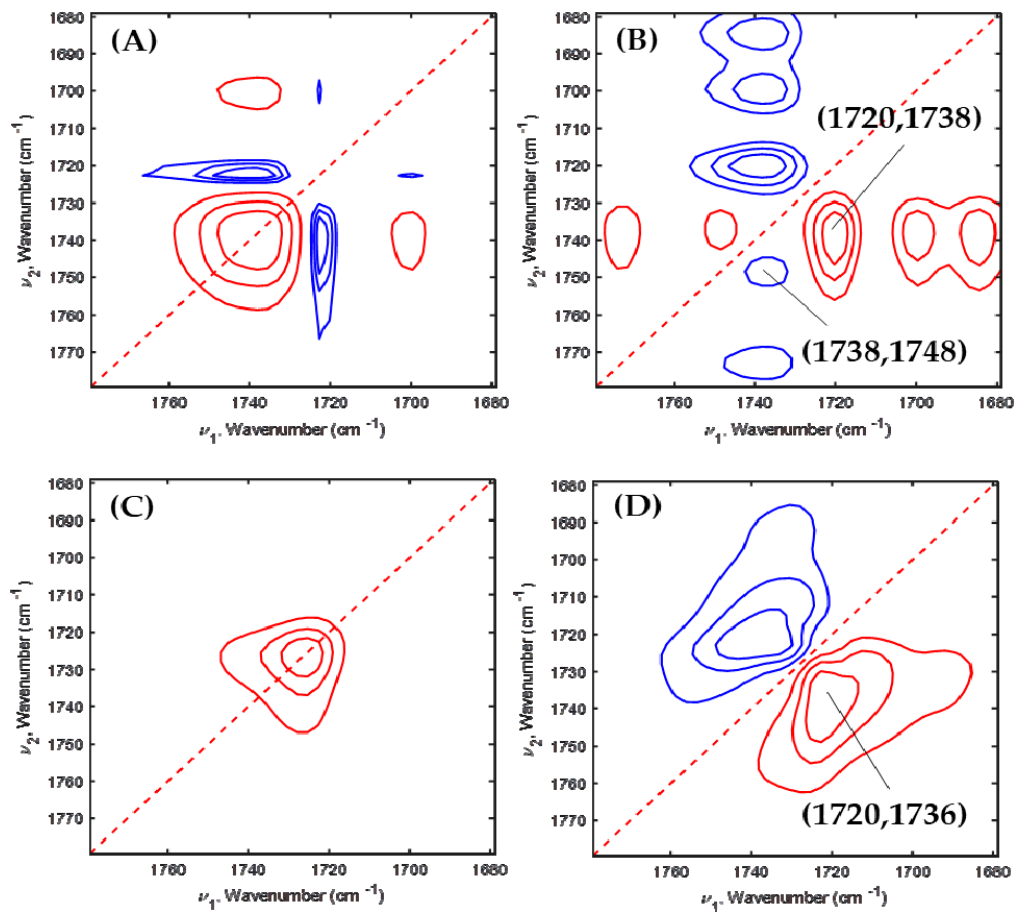

Figure 7. Synchronous $(\mathbf{A}, \mathbf{C})$ and asynchronous (B,D) 2D correlation spectra obtained from Figure 4E,F.

\section{Conclusions}

The chemical IR images of PHBHx/PEG blends during the heating process were measured to investigate the existence of domains in films of PHBHx/PEG (high molecular weight) blends. In the chemical images, domains were observed in PHBHx/PEG $=60 / 40$ and 50/50 blends. With the increase in PEG content, a new band at $1748 \mathrm{~cm}^{-1}$ assignable to the amorphous partial mixture of PHBHx and PEG appeared. As the mixing of PEG, which acts as a plasticizer, will substantially decrease the $T_{\mathrm{g}}$ and increase the molecular mobility of $\mathrm{PHBHx}$, we expect the crystallization kinetics will be affected. The results of temperature-dependent FTIR spectra in the domains of the PHBHx/PEG blends revealed that PEG plays an important role in changing the kinetics and degree of PHBHx crystallization. Therefore, PEG can have an effect on changing the thermal behavior of PHBHx copolymers.

Supplementary Materials: The following are available online at http:/ /www.mdpi.com/2073-4360/11/3/507/s1, Figure S1: SEM image of cross section of spin-coated PHBHx/PEG $=70 / 30$ blend film on Pt wafer. The arrow indicates the thickness of the PHBHx/PEG $=70 / 30$ blend film.

Author Contributions: Conceptualization and methodology, Y.M.J.; performed experiments, S.J., Y.P., S.M.K., and B.C.; data curation, Y.P. and S.J.; 2D correlation analysis, Y.P. and I.N.; writing-original draft preparation, Y.P.; writing-review and editing, Y.M.J. and I.N.; supervision, Y.M.J.; funding acquisition, Y.M.J. All authors discussed and approved the final version.

Funding: This research was supported by the National Research Foundation of Korea (NRF) grants funded by the Ministry of Science, NRF-2018R1A6A3A11050387.

Acknowledgments: Experiments at PLS-II were supported in part by MSICT and POSTECH.

Conflicts of Interest: The authors declare no conflict of interest. The funders had no role in the design of the study; in the collection, analyses, or interpretation of data; in the writing of the manuscript, or in the decision to publish the results.

\section{References}

1. Rhodes, C.J. Plastic pollution and potential solutions. Sci. Prog. 2018, 101, 207-260. [CrossRef] [PubMed]

2. Mar, I. The known unknowns of plastic pollution. The Economist, 3 March 2018. 
3. Thompson, R.C.; Moore, C.J.; vom Saal, F.S.; Swan, S.H. Plastics, the environment and human health: Current consensus and future trends. Philos. Trans. R. Soc. Lond. B. Biol. Sci. 2009, 364, 2153-2166. [CrossRef]

4. Rujnić-Sokele, M.; Pilipović, A. Challenges and opportunities of biodegradable plastics: A mini review. Waste Manag. Res. 2017, 35, 132-140. [CrossRef] [PubMed]

5. Sobieski, B. Characterization of a Bio-Based, Biodegradable Class of Copolymers, Poly [(R)-3-Hydroxybutyrateco-(R)-3-Hydroxyhexanoate], and Application Development. Ph.D. Thesis, University of Delaware, Newark, DE, USA, 2017.

6. Sobieski, B.; Chase, B.; Noda, I.; Rabolt, J. Artifact correction in temperature-dependent attenuated total reflection infrared (ATR-IR) spectra. Appl. Spectrosc. 2017, 71, 1868-1875. [CrossRef]

7. Noda, I.; Blake Lindsey, S.; Caraway, D. Nodax ${ }^{\mathrm{TM}}$ class PHA copolymers: Their properties and applications. In Plastics from Bacteria; Springer: Berlin/Heidelberg, Germany, 2009; Volume 14, pp. 237-255.

8. Marlina, D.; Sato, H.; Hoshina, H.; Ozaki, Y. Intermolecular interactions of poly(3-hydroxybutyrate-co3-hydroxyvalerate) (P(HB-co-HV)) with PHB-type crystal structure and PHV-type crystal structure studied by low-frequency Raman and terahertz spectroscopy. Polymer 2018, 135, 331-337. [CrossRef]

9. Loh, X.J.; Zhang, Z.; Wu, Y.; Lee, T.S. Synthesis of novel biodegradable thermoresponsive triblock copolymers based on poly [(R)-3-hydroxybutyrate] and poly ( $N$-isopropylacrylamide) and their formation of thermoresponsive micelles. Macromolecules 2009, 42, 194-202. [CrossRef]

10. Noda, I.; Roy, A.; Carriere, J.; Sobieski, B.J.; Chase, D.B.; Rabolt, J.F. Two-dimensional Raman correlation spectroscopy study of poly[(R)-3-hydroxybutyrate-co-(R)-3-hydroxyhexanoate] copolymers. Appl. Spectrosc. 2017, 71, 1427-1431. [CrossRef]

11. Rajaratanam, D.D.; Ariffin, H.; Hassan, M.A.; Nik Abd Rahman, N.M.A.; Nishida, H. In vitro cytotoxicity of superheated steam hydrolyzed oligo((R)-3-hydroxybutyrate-co-(R)-3-hydroxyhexanoate) and characteristics of its blend with poly(L-lactic acid) for biomaterial applications. PLoS ONE 2018, 13, e0199742. [CrossRef]

12. Lim, J.; You, M.; Li, J.; Li, Z. Emerging bone tissue engineering via polyhydroxyalkanoate (PHA)-based scaffolds. Mater. Sci. Eng. C 2017, 79, 917-929. [CrossRef]

13. Chee, M.J.K.; Ismail, J.; Kummerlöwe, C.; Kammer, H.W. Study on miscibility of PEO and PCL in blends with PHB by solution viscometry. Polymer 2002, 43, 1235-1239. [CrossRef]

14. Armentano, I.; Fortunati, E.; Burgos, N.; Dominici, F.; Luzi, F.; Fiori, S.; Jiménez, A.; Yoon, K.; Ahn, J.; Kang, S.; et al. Processing and characterization of plasticized PLA/PHB blends for biodegradable multiphase systems. Express Polym. Lett. 2015, 9, 583-596. [CrossRef]

15. Vanovčanová, Z.; Alexy, P.; Feranc, J.; Plavec, R.; Bočkaj, J.; Kalináková, L.; Tomanová, K.; Perd'ochová, D.; Šariský, D.; Gálisová, I. Effect of PHB on the properties of biodegradable PLA blends. Chem. Pap. 2016, 70, 1408-1415. [CrossRef]

16. Sobieski, B.J.; Gong, L.; Aubuchon, S.R.; Noda, I.; Chase, D.B.; Rabolt, J.F. Thermally reversible physical gels of poly[(R)-3-hydroxybutyrate-co-(R)-3-hydroxyhexanoate ]: Part 1 gelation in dimethylformamide. Polymer 2017, 131, 217-223. [CrossRef]

17. Lim, J.; Kim, J. UV-photodegradation of poly(3-hydroxybutyrate-co-3-hydroxyhexanoate) (PHB-HHx). Macromol. Res. 2016, 24, 9-13. [CrossRef]

18. Liu, Q.; Zhang, H.; Deng, B.; Zhao, X. Poly(3-hydroxybutyrate-co-3-hydroxyvalerate): structure, property, and fiber. Int. J. Polym. Sci. 2014, 2014. [CrossRef]

19. Padermshoke, A.; Katsumoto, Y.; Sato, H.; Ekgasit, S.; Noda, I.; Ozaki, Y. Surface melting and crystallization behavior of polyhydroxyalkanoates studied by attenuated total reflection infrared spectroscopy. Polymer 2004, 45, 6547-6554. [CrossRef]

20. Yeo, J.C.C.; Muiruri, J.K.; Tan, B.H.; Thitsartarn, W.; Kong, J.; Zhang, X.; Li, Z.; He, C. Biodegradable PHB-rubber copolymer toughened PLA green composites with ultrahigh extensibility. ACS Sustain. Chem. Eng. 2018, 6, 15517-15527. [CrossRef]

21. Townsend, K.J.; Busse, K.; Kressler, J.; Scholz, C. Contact angle, WAXS, and SAXS analysis of poly( $\beta$-hydroxybutyrate) and poly(ethylene glycol) block copolymers obtained via Azotobacter vinelandii UWD. Biotechnol. Prog. 2005, 21, 959-964. [CrossRef] [PubMed]

22. Leng Pak, Y.; Ahmad, M.; Kamyar, S.; Yunus, W.; Ibrahim, N.; Zainuddin, N. Mechanical and morphological properties of poly-3-hydroxybutyrate/poly(butyleneadipate-co-terephthalate)/layered double hydroxide nanocomposites. J. Nanomater. 2013, 2013. [CrossRef] 
23. Hoshina, H.; Morisawa, Y.; Sato, H.; Minamide, H.; Noda, I.; Ozaki, Y.; Otani, C. Polarization and temperature dependent spectra of poly(3-hydroxyalkanoate)s measured at terahertz frequencies. Phys. Chem. Chem. Phys. 2011, 13, 9173-9179. [CrossRef]

24. Cristina Reis, K.; Pereira, L.; Cristina Nogueira Alves Melo, I.; Manoel Marconcini, J.; Trugilho, P.; Tonoli, G.H.D. Particles of coffee wastes as reinforcement in polyhydroxybutyrate (PHB) based composites. Mater. Res. 2015, 18, 546-552. [CrossRef]

25. Beber, V.C.; de Barros, S.; Banea, M.D.; Brede, M.; de Carvalho, L.H.; Hoffmann, R.; Costa, A.R.M.; Bezerra, E.B.; Silva, I.D.S.; Haag, K.; et al. Effect of babassu natural filler on PBAT/PHB biodegradable blends: an investigation of thermal, mechanical, and morphological behavior. Materials 2018, 11, 820. [CrossRef] [PubMed]

26. Kim, M.K.; Ryu, S.R.; Noda, I.; Jung, Y.M. Projection 2D correlation analysis of spin-coated film of biodegradable P(HB-co-HHx)/PEG blend. Vib. Spectrosc. 2012, 60, 163-167. [CrossRef]

27. Kim, M.K.; Ryu, R.; Noda, I.; Jung, Y.M. 2D correlation analysis of spin-coated films of biodegradable P (HB-co-HHx)/PEG blends. Bull. Korean Chem. Soc. 2011, 32, 4005-4010. [CrossRef]

28. Choi, H.C.; Ryu, S.R.; Ji, H.; Kim, S.B.; Noda, I.; Jung, Y.M. Two-dimensional heterospectral correlation analysis of X-ray photoelectron spectra and infrared spectra for spin-coated films of biodegradable poly(3-hydroxybutyrate-co-3-hydroxyhexanoate) copolymers. J. Phys. Chem. B 2010, 114, 10979-10985. [CrossRef]

29. Ji, H.; Kim, S.B.; Noda, I.; Jung, Y.M. Details of thermal behavior of spin-coated film of biodegradable poly(3-hydroxybutyrate-co-3-hydroxyhexanoate) copolymer studied by principal component analysis-based two-dimensional (PCA2D) correlation spectroscopy. Spectrochim. Acta-Part A Mol. Biomol. Spectrosc. 2009, 71, 1873-1876. [CrossRef] [PubMed]

30. Chen, Y.; Park, Y.; Noda, I.; Jung, Y.M. Influence of polyethylene glycol (PEG) chain length on the thermal behavior of spin-coated thin films of biodegradable poly(3-hydroxybutyrate-co-3-hydroxyhexanoate)/PEG blends. J. Mol. Struct. 2016, 1124, 159-163. [CrossRef]

31. Chen, Y.; Noda, I.; Jung, Y.M. Influence of polyethylene glycol on the phase transition of poly(butylene adipate) thin films: Polymorphic control. Spectrochim. Acta Part A Mol. Biomol. Spectrosc. 2017, 184, 228-234. [CrossRef]

32. Chen, Y.; Park, Y.; Yang, C.; Noda, I.; Jung, Y.M. Reorientation of the poly(3-hydroxybutyrate-co3-hydroxyhexanoate) crystal in thin film induced by polyethylene glycol. Polymer 2017, 120, 59-67. [CrossRef]

33. Chon, Y.J.; Koo, J.M.; Park, Y.J.; Hwang, S.Y.; Jung, Y.M.; Im, S.S. Synthesis of a high-performance citric acid-based polyester elastomer by a hot-pressing technique. Polymer 2017, 125, 283-291. [CrossRef]

34. Park, Y.; Hashimoto, C.; Hashimoto, T.; Hirokawa, Y.; Jung, Y.M.; Ozaki, Y. Reaction-induced self-assembly of gel structure: A new insight into chemical gelation process of $\mathrm{N}$-isopropylacrylamide as studied by two-dimensional infrared correlation spectroscopy. Macromolecules 2013, 46, 3587-3602. [CrossRef]

35. Noda, I. Advances in Two-dimensional correlation spectroscopy (2DCOS). In Frontiers and Advances in Molecular Spectroscopy; Elsevier: Amsterdam, The Netherlands, 2018; pp. 47-75. ISBN 9780128112212.

36. Noda, I.; Ozaki, Y. Two-Dimensional Correlation Spectroscopy-Applications in Vibrational and Optical Spectroscopy; John Wiley \& Sons, Ltd.: Chichester, UK, 2004; ISBN 9780470012406.

37. Park, Y.; Jin, S.; Noda, I.; Jung, Y.M. Recent progresses in two-dimensional correlation spectroscopy (2D-COS). J. Mol. Struct. 2018, 1168,1-21. [CrossRef]

38. Young Mee, J.; Noda, I. New Approaches to generalized two-dimensional correlation spectroscopy and its applications. Appl. Spectrosc. Rev. 2006, 41, 515-547. [CrossRef]

39. Vogel, C.; Wessel, E.; Siesler, H.W. FT-IR imaging spectroscopy of phase separation in blends of poly(3-hydroxybutyrate) with poly(1-lactic acid) and poly( $\epsilon$-caprolactone). Biomacromolecules 2008, 9, 523-527. [CrossRef]

40. Ishikawa, D.; Nishii, T.; Mizuno, F.; Sato, H.; Kazarian, S.G.; Ozaki, Y. Potential of a newly developed high-speed near-infrared (NIR) camera (Compovision) in polymer industrial analyses: Monitoring crystallinity and crystal evolution of polylactic acid (PLA) and concentration of PLA in PLA/poly-(R)-3-hydroxybutyrate (PHB) blend. Appl. Spectrosc. 2013, 67, 1441-1446. [PubMed]

41. Sato, H.; Murakami, R.; Padermshoke, A.; Hirose, F.; Senda, K.; Noda, I.; Ozaki, Y. Infrared spectroscopy studies of $\mathrm{CH} \cdots \mathrm{O}$ hydrogen bondings and thermal behavior of biodegradable poly(hydroxyalkanoate). Macromolecules 2004, 37, 7203-7213. [CrossRef] 
42. Sobieski, B.J.; Noda, I.; Rabolt, J.F.; Chase, D.B. Observation of intermolecular hydrogen bonding interactions in biosynthesized and biodegradable poly [(R)-3-hydroxybutyrate-co-(R)-3-hydroxyhexanoate] in chloroform and 1,1,1,3,3,3-Hexafluoro-2-propanol (HFIP). Appl. Spectrosc. 2017, 71, 2339-2343. [CrossRef] [PubMed]

43. Zhao, Q.; Cheng, G. Biodegradable PHB/PEG derivatives and their degradation behavior. In New Frontiers in Polymer Research; Nova Science publishers, Inc.: New York, NY, USA, 2006; pp. 99-124. 